\title{
The Influence of Career Choice Motivation and Academic Achievement on Academic Resilience
}

\author{
Uly Pramuditya Isnaini ${ }^{1, *}$ Winny Setyonugroho ${ }^{2}$, Erna Rochmawati ${ }^{2}$
}

\author{
${ }^{I}$ Faculty of Medicine of the Universitas Islam Indonesia \\ ${ }^{2}$ Faculty of Medicine and Health Sciences of the Universitas Muhammadiyah Yogyakarta \\ *Corresponding author: uly.pramuditya.isnaini@uii.ac.id
}

\begin{abstract}
Background: The world faces a labor crisis and high incidence of dropouts. A shortage of health workers is predicted to reach 12.9 million by 2035. Being dropped out of school is marked by a decline in students' achievement due to the loss of orientation and motivation. A declining achievement is an indicator of students' low academic resilience.

Aim: This study aimed to analyze the influence of career choice motivation, CBT, and OSCE scores on academic resilience.

Methods: This study was a quantitative study with a cross-sectional design conducted in an undergraduate nursing program. The respondents were selected using the convenience sampling technique, which resulted in 325 students as the research participants. The data collection used the HCC and ARS-30 questionnaires.

Results: The results of this study showed that career choice motivation influenced academic resilience while CBT and OSCE scores did not affect academic resilience. Career choice motivation, CBT, and OSCE scores simultaneously affected students' academic resilience by $38.7 \%$.

Conclusion: Academic resilience is influenced by career choice motivation, CBT scores, OSCE scores, and other factors not examined in this study. Other possible contributing factors in academic resilience are educational environment and student personality.
\end{abstract}

Keywords: Career Choice Motivation, Academic Achievement, Academic Resilience.

\section{INTRODUCTION}

The world is facing a labor crisis. The nurse workforce will increase by almost 3.24 million in 2022, but this figure remains inadequate compared to the number of nurses needed [1]. The World Health Organization (WHO) in 2014 stated that the predicted shortage of health workers will reach 12.9 million by 2035 [2]. One cause of nursing shortage is the large number of new nurses who leave work due to incompatible career competencies [2,3].

The shortage of nurses that will occur in the future is caused by the presence of nurses who leave nursing work because they either retire or change jobs. A total of 1,200 nurses come out each year [2]. Nursing fresh graduates are the nursing workforce who mostly leave jobs. One study found that $36 \%$ nurses aged $24-29$ years wanted to leave the nursing profession while $35 \%$ nurses aged 35 years intended to quit the nursing job [3].

The same job is caused by the presence of nurses who leave the job. The work given is monotonous and not in accordance with the competence [3]. Research conducted on 569 students in Korea found that $85 \%$ of the students changed their career paths [4].

Another problem is the high incidence of dropouts at educational institutions. The percentage of nursing students who were unable to survive and being dropped out reached $20-40 \%$ in the UK, $10-40 \%$ in Canada, and $20-50 \%$ in the Netherlands $[5,6]$. In this condition, $50 \%$ of total nursing students experienced psychological fatigue while $25 \%$ experienced chronic depression or anxiety [7].

In another study, nursing students' career motivation only lasted in the first and second academic years. After that, students often lose the goal orientation of their chosen career [8]. The impact of losing the goal orientation and learning motivation is the decline in student achievement [9] while learning motivation is influenced by career choice motivation.

Furthermore, career choice motivation is influenced by individual and environmental conditions [10]. Parents' work history, exposure from the world of health, past 
experiences related to health, and parental motivation are also factors that influence career choices [10]. Remuneration or reward factor is the most influencing factor in career choices among medical, dentistry, pharmacy, and nursing students [11]. Other studies stated that family has a great influence on career choices, especially nursing careers [11]. Other research found that self-efficacy is the least influential factor, while exposure to health is the most influencing factor, in nursing career choices [2]. This indicates that numerous factors can influence career choice motivation, and these factors then influence the academic skills when they are undergoing the educational process [10], so that students have academic resilience.

Academic resilience is the capacity of students as a result of the process of overcoming difficulties and maintaining goals during the educational process $[9,10$, 12, 13]. Academic resilience is identified through cognitive and non-cognitive abilities [14]. Achievement is an indicator of students' academic resilience and educational success $[9,15]$.

\section{METHODS}

\subsection{Research design}

This study was a cross-sectional survey design with data collected from undergraduate nursing students through completion of the instrument: Healthcare Career Choice (HCC) Questionnaire and Academic Resilience Scale 30 (ARS-30) Questionnaire.

\subsection{Study instruments}

The demographic questionnaire sought information about participants' gender, level of academic years, level of parents' education, level of parents' job, and level of parents' income. The study utilized two instruments: HCC Questionnaire and ARS-30.

HCC was used to measure students' career choice motivation. The response options for the items in HCC are 5 for strongly agree, 4 for agree, 3 for uncertain, 2 for disagree, 1 for strongly disagree. The range of the global score is $0-175$, in which a higher score indicates higher career choice motivation. The HCC Questionnaire has been validated with the Cronbach's alpha factor of 0.93 [16]. HCC consists of six domains, including:

- Personal interest (5 items)

- Prior healthcare exposure (6 items)

- Self-efficacy (4 items)

- Perceived nature of work (5 items)

- Job prospects (7 items)

- Social influences (8 items)
ARS-30 was used to measure students' academic resilience. The response options for the items in ARS-30 are 5 for strongly agree, 4 for agree, 3 for uncertain, 2 for disagree, 1 for strongly disagree. The range of the global score is $0-150$, in which a higher score indicates higher academic resilience. The ARS-30 has been validated with the Cronbach's alpha factor $1=0.83$, factor $2=0.78$, and factor $3=0.80$ [14]. ARS-30 consists of three domains, including:

- Perseverance (14 items)

- Reflecting and adaptive help seeking (9 items)

- Negative affect and emotional response (7 items)

\subsection{Procedure}

The population of this study was 443 students. The research sample was selected using the convenience sampling technique. The samples obtained in this study were $325(73.4 \%)$ students. The data for career choice motivation and academic resilience were obtained from the questionnaires given to students in class and social media. The data on academic achievement values consisted of CBT and OSCE scores obtained from the Nursing Study Program Managers.

\subsection{Ethical consideration}

The approval to conduct the study was granted by the Institutional Research Ethics Committee. The study materials included a participant information sheet, a consent form, and questionnaires. The students received some explanation about the research purposes, quality assurance, and research procedure. They also signed the informed consent before completing the questionnaire as they were promised that the answer would remain confidential.

\subsection{Data analysis}

The analysis was determined based on the scale of measurement, the normal distribution of data, and the variance homogeneity. The statistical test used in this study was the multiple linear regression test.

\section{RESULTS}

Table 1 shows the overall scores and total mean scores for each domain in the HCC Questionnaire. The first academic year has the highest career choice motivation score (79.9). The factors in career choice motivation with high scores are personal interest (PI) and perceived nature of work (PNW). The low-score factors are prior healthcare exposure (PHE) and job prospects (JP) 
Table 1

Mean (SD) HCC item scores based on the level of academic years

\begin{tabular}{|c|c|c|c|}
\hline Year & $\mathrm{HCC}$ & Mean \pm SD & Min-Max \\
\hline \multirow{7}{*}{ Year $4(n=83)$} & Personal Interest & $82.4 \pm 8.9$ & $64-100$ \\
\hline & Prior Healthcare Exposure & $71.5 \pm 12.1$ & $43-100$ \\
\hline & Self-Efficacy & $75.9 \pm 10.7$ & $50-100$ \\
\hline & Perceived Nature of Work & $79.3 \pm 11.2$ & $36-100$ \\
\hline & Job Prospects & $73.5 \pm 11.9$ & $46-100$ \\
\hline & Social Influences & $75.2 \pm 9.9$ & $50-98$ \\
\hline & Mean score & $76.4 \pm 8.3$ & $59-97$ \\
\hline \multirow[t]{7}{*}{ Year $3(n=61)$} & Personal Interest & $81.9 \pm 11.0$ & $48-100$ \\
\hline & Prior Healthcare Exposure & $69.9 \pm 13.7$ & $40-97$ \\
\hline & Self-Efficacy & $74.3 \pm 11.2$ & $50-95$ \\
\hline & Perceived Nature of Work & $77.0 \pm 11.0$ & $56-100$ \\
\hline & Job Prospects & $73.1 \pm 13.3$ & $40-100$ \\
\hline & Social Influences & $73.7 \pm 11.7$ & $43-100$ \\
\hline & Mean score & $75.1 \pm 9.5$ & $54-94$ \\
\hline \multirow[t]{7}{*}{ Year $2(n=87)$} & Personal Interest & $85.9 \pm 12.7$ & $28-100$ \\
\hline & Prior Healthcare Exposure & $74.4 \pm 13.4$ & $20-100$ \\
\hline & Self-Efficacy & $76.8 \pm 13.4$ & $45-100$ \\
\hline & Perceived Nature of Work & $81.6 \pm 13.0$ & $36-100$ \\
\hline & Job Prospects & $79.1 \pm 12.3$ & $46-100$ \\
\hline & Social Influences & $78.8 \pm 13.3$ & $25-100$ \\
\hline & Mean score & $79.5 \pm 10.8$ & $35-99$ \\
\hline \multirow[t]{7}{*}{ Year $1(n=94)$} & Personal Interest & $86.9 \pm 9.9$ & $64-100$ \\
\hline & Prior Healthcare Exposure & $74.0 \pm 11.9$ & $40-100$ \\
\hline & Self-Efficacy & $78.1 \pm 12.5$ & $55-100$ \\
\hline & Perceived Nature of Work & $81.7 \pm 10.7$ & $60-100$ \\
\hline & Job Prospects & $78.5 \pm 11.8$ & $49-100$ \\
\hline & Social Influences & $79.6 \pm 10.9$ & $53-100$ \\
\hline & Mean score & $79.9 \pm 8.7$ & $57-100$ \\
\hline
\end{tabular}

Table 2 shows the trend of the scores for CBT and OSCE exams. The third (2016) academic year has the highest CBT score, and the fourth (2015) academic year has the highest OSCE score.

Table 3 shows the overall scores and total mean scores for each domain in the ARS-30. The first academic year (78.0) has a higher score than the second (77.7), fourth (76.7), and third (75.0) academic year. Meanwhile, the forming factors in academic resilience with high scores are reflecting and adaptive help seeking. The lowscore factors are negative affect and emotional response.

Table 2

Trend of CBT and OSCE scores based on the level of academic years

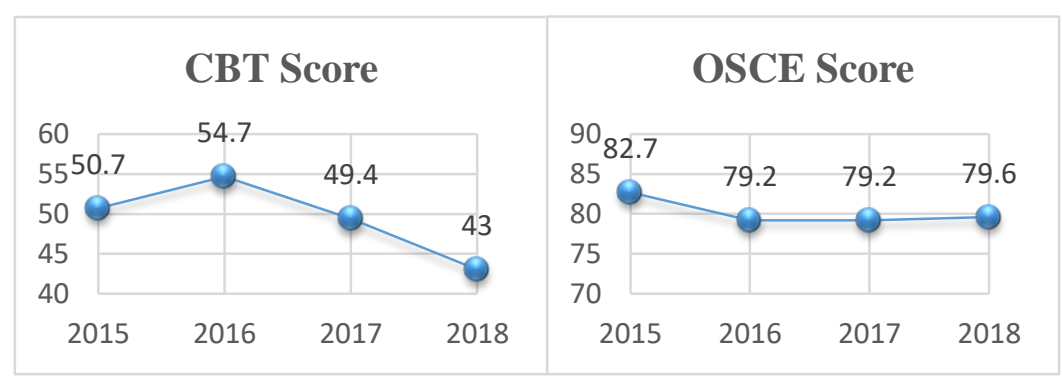


Table 3

Mean (SD) ARS-30 item scores based on the level of academic years

\begin{tabular}{clcc}
\hline \multicolumn{1}{c}{ Year } & \multicolumn{1}{c}{ ARS-30 } & Mean \pm SD & Min - Max \\
\hline Year 4 $(\mathrm{n}=83)$ & Perseverance & $79.0 \pm 7.6$ & $60-94$ \\
& Reflecting \& Adaptive Help Seeking & $80.8 \pm 8.5$ & $56-100$ \\
& Negative Affect \& Emotional Response & $70.4 \pm 6.6$ & $54-89$ \\
\cline { 2 - 4 } & Mean score & $\mathbf{7 6 . 7} \pm \mathbf{7 . 6}$ & $\mathbf{5 7 - 9 4}$ \\
\hline Year 3 $(\mathrm{n}=61)$ & Perseverance & $77.4 \pm 8.1$ & $59-91$ \\
& Reflecting \& Adaptive Help Seeking & $79.0 \pm 11.2$ & $49-100$ \\
& Negative Affect \& Emotional Response & $68.6 \pm 8.0$ & $54-86$ \\
\cline { 2 - 4 } & Mean score & $\mathbf{7 5 . 0} \pm \mathbf{9 . 1}$ & $\mathbf{5 4 - 9 2}$ \\
\hline Year 2 $(\mathrm{n}=87)$ & Perseverance & $80.1 \pm 9.3$ & $43-96$ \\
& Reflecting \& Adaptive Help Seeking & $83.3 \pm 11.5$ & $20-100$ \\
& Negative Affect \& Emotional Response & $69.6 \pm 8.3$ & $51-89$ \\
\cline { 2 - 4 } & Mean score & $\mathbf{7 7 . 7} \pm \mathbf{6 . 4}$ & $\mathbf{3 8 - 9 5}$ \\
\hline Year 1 $(\mathrm{n}=94)$ & Perseverance & $80.3 \pm 8.4$ & $57-97$ \\
& Reflecting \& Adaptive Help Seeking & $82.5 \pm 10.6$ & $58-100$ \\
& Negative Affect \& Emotional Response & $71.2 \pm 8.3$ & $46-89$ \\
\cline { 2 - 4 } & Mean score & $\mathbf{7 8 . 0} \pm \mathbf{9 . 1}$ & $\mathbf{5 4 - 9 5}$ \\
\hline
\end{tabular}

Table 4 shows the results of multiple linear regression test between career choice motivation, CBT, OSCE, and academic resilience. The multiple linear regression test conducted in this study shows that there are influences of career choice motivation on academic resilience, whereas academic achievement has no effects on academic resilience. Career choice motivation and academic achievement have an influence on academic resilience by $48.7 \%$ in the fourth academic year, $33.9 \%$ in the third academic year, $39.3 \%$ in the second academic year, and $32.9 \%$ in the first academic year.

Table 4

Multiple linear regression test between career choice motivation, CBT, OSCE, and academic resilience

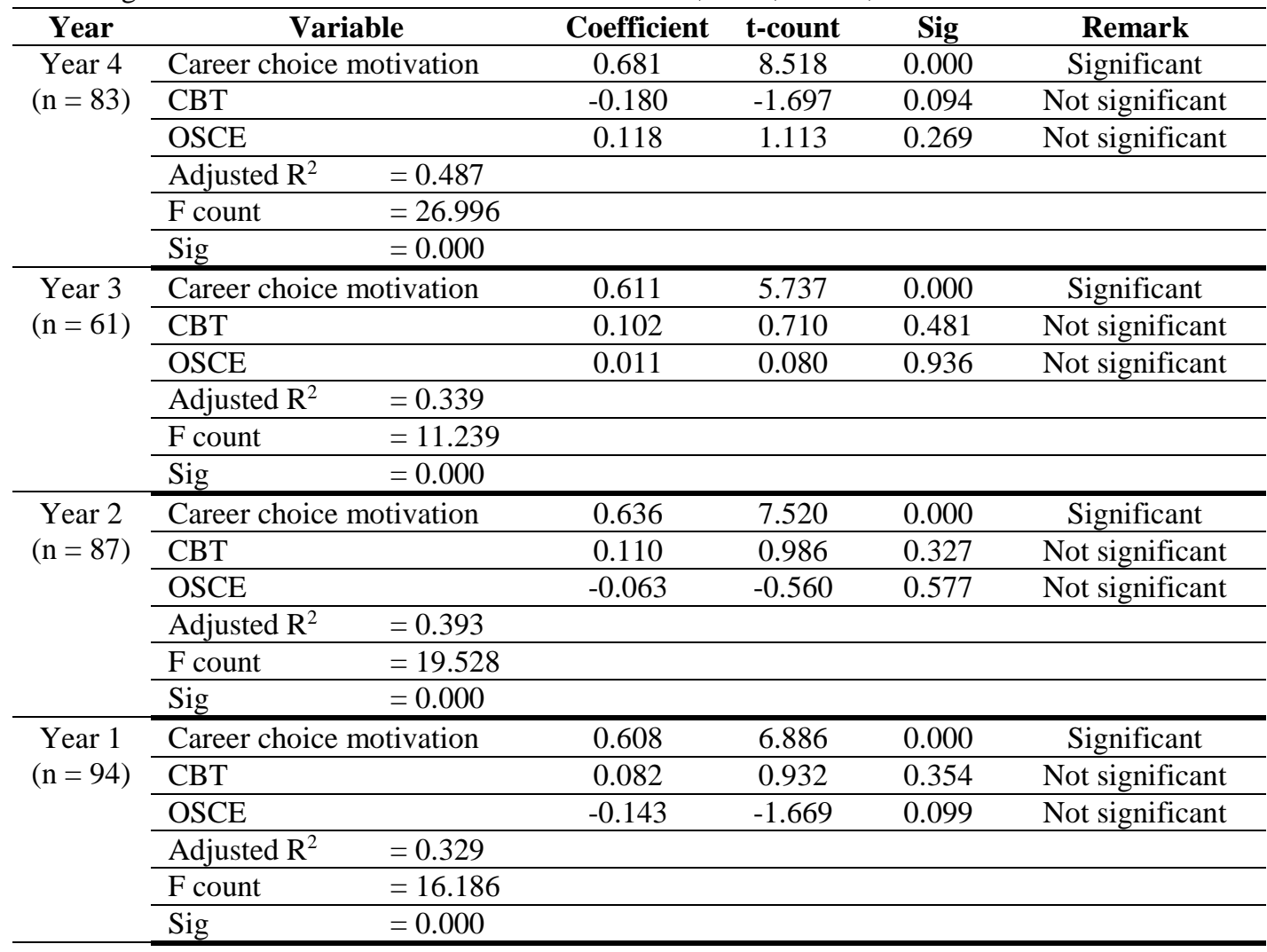




\section{DISCUSSION}

In the career choice motivation variable, the first dominant factor is personal interest (PI) which consists of the desire to help others and a career desire in the world of health. PI is the dominant factor in some countries because of the high nature of altruism in nursing careers $[2,11]$.

Interest in nursing careers is satisfied when they can help others in need. Students with PI dominant factors will also have better academic resilience and lower levels of depression than students who have career choice motivation affected by other factors $[2,17,18]$.

The second dominant factor, perceived nature of work (PNW), is motivation derived from the nature of work that will be felt in the future. PNW consists of job security, job self-esteem, and job autonomy [11]. Students who perceive that the main demands of a career are adequate security, respect, and autonomy of employment will have a career choice motivation with PNW factors being more dominant $[17,18]$. In developing countries, PNW is more dominant than PI. Conversely, in developed countries, PI is more dominant than PNW. This happens because the basic human needs in the form of security, appreciation, and autonomy have been fulfilled, thereby increasing self-actualization needs $[17,18]$. This pattern also occurs in Indonesia.

The first non-dominant factor, prior healthcare exposure (PHE), is motivation that is influenced by the high exposure to the world of health originating from outside [2]. In developing countries, information exposure to the world of nursing remains low, thus resulting in career choice motivation with PHE factors also being low [19]. Such patterns in developing countries also occur in Indonesia.

The second non-dominant factor, job prospects (JP), is motivation derived from the financial value that will be obtained from work. In line with the previous literature, JP is a non-dominant factor because prospective students consider nursing careers do not guarantee financial fulfillment $[2,11]$.

The level of career choice motivation has the same pattern as the level of academic resilience among the students. This result is in line with research in Texas, United States which indicates that career choice motivation will decline in the second and third academic years and then will rise again in the fourth academic year [20]. Previous literature suggests that stress and conflict levels tend to increase in the second and third academic years of the study [18]. In the first academic year, students' idealism is still high but slowly falls along with the conflicts they experience during their studies. The more conflicts that are passed, the more they increase students' academic resilience [21,22]. The patterns that occur in all academic years indicate that each stage they go through has different characteristics. The first academic year shows fairly high career choice motivation, CBT and OSCE scores, and high academic resilience. This is due to the stable adaptation process which continues to be performed by new students. In addition, the orientation towards academic success remains high, thereby encouraging continuously good performance during the educational process.

The second academic year has a pattern that tends to show a decrease in career choice motivation, OSCE scores, and academic resilience although the decrease is insignificant. The CBT score has an increasing pattern only from the first academic year to the second academic year. Previous research has shown that the second academic year is synonymous with a phase of academic decline [23]. The second academic year is strongly influenced by the relationship between students-lecturers and students-peers. The phase of academic decline can be identified through decreased interest, decreased grades, increased absenteeism, and the most severe being dropping out of school [23].

The third academic year indicates significantly decreased levels of career choice motivation, OSCE scores, and academic resilience. It is possible that the phase of academic decline usually occurring in the second academic year does not occur until the third academic year. This phase is characterized by high academic doubts and anxiety. Students' coping skills in this phase are needed.

The fourth academic year has a pattern of career choice motivation levels, OSCE scores, and academic resilience that start to increase and become stable. Increased career choice motivation, OSCE scores, and academic resilience are determined by orientation, patterns of interaction with lecturers and peers, and the personality that has been formed since the first academic year of the educational process. Students with poor orientation, interaction patterns, and personality since the first academic year tend to experience feelings of anxiety. stress, fatigue, and even depression in the final academic year [23]. Then there needs to be an intervention to maintain orientation, interaction patterns, and personality, especially for second and third academicyear students.

This study found that the career choice motivation, CBT scores, and OSCE scores simultaneously affected academic resilience by $48.7 \%$ in the fourth academic year, $33.9 \%$ in the third academic year, $39.3 \%$ in the second academic year, and $32.9 \%$ in the first academic year. On average, only $38.7 \%$ of career choice motivation, CBT scores, and OSCE scores affected students' academic resilience. The rest $61.3 \%$ has other factors that influence academic resilience. Previous literature has found that the educational environment and student personality are the dominant factors affecting academic resilience $[10,19,20,24,25,26]$.

\section{LIMITATIONS}

This study has provided information on students' career choice motivation, academic achievement, and academic resilience. However, the number of students in the third academic year was lower than that in the other academic years. Also, the academic achievement data were not fulfilled, and this study was likely to have confounding variables, such as students' personality and 
educational environment, which were not investigated here in.

\section{CONCLUSION}

This study has shown that career choice motivation influences academic resilience. The dominant factors in career choice motivation are personal interest and perceived nature of work, while the non-dominant factors are prior healthcare exposure and job prospects. In addition, academic achievement does not influence the academic resilience of the students, whereas career choice motivation and academic achievement simultaneously influence academic resilience by $38.7 \%$.

\section{AUTHORS' CONTRIBUTIONS}

The authors' contribution in this study includes data design, data collection, analysis, and interpretation with support from the supervisors.

\section{ACKNOWLEDGMENTS}

The authors would like to thank all of the students and lecturers in the Undergraduate Nursing Program of Universitas Muhammadiyah Yogyakarta as well as the supervisors.

\section{REFERENCES}

[1] Yarbrough, S., Martin, P., Alfred, D., McNeill, C., 2017. Professional values, job satisfaction, career development, and intent to stay. Nurs. Ethics 24, 675685. https://doi.org/10.1177/0969733015623098

[2] Liaw, S.Y., Wu, L.T., Chow, Y.L., Lim, S., Tan, K.K., 2017. Career choice and perceptions of nursing among healthcare students in higher educational institutions. Nurse Educ. Today 52, 66-72. https://doi.org/10.1016/j.nedt.2017.02.008

[3] Pasila, K., Elo, S., Kääriäinen, M., 2017. Newly graduated nurses' orientation experiences: A systematic review of qualitative studies. Int. J. Nurs. Stud. 71, 1727. https://doi.org/10.1016/j.ijnurstu.2017.02.021

[4] Lee, K.A., Kim, J., 2015. Nursing Students' Awareness of Career Decision-making Self-efficacy, Career Search Behavior and Commitment to Career Choice. Perspect. Nurs. Sci. 12, 42. https://doi.org/10.16952/pns.2015.12.1.42

[5] Clements, A.J., Kinman, G., Leggetter, S., Teoh, K., Guppy, A., 2016. Exploring commitment, professional identity, and support for student nurses. Nurse Educ. Pract. 16, 20-26. https://doi.org/10.1016/j.nepr.2015.06.001
[6] Willis, G., 2015. Shape of caring review. https://hee.nhs.uk/2015/03/12/the-shape-ofcaringreview-report-published. Accessed October 2018

[7] Dyrbye, L.N., Power, D.V., Massie, F.S., Eacker, A., Harper, W., Thomas, M.R., Szydlo, D.W., Sloan, J.A., Shanafelt, T.D., 2010. Factors associated with resilience to and recovery from burnout: a prospective, multiinstitutional study of US medical students: Resilience in medical students. Med. Educ. 44, 1016-1026. https://doi.org/10.1111/j.1365-2923.2010.03754.x

[8] ten Hoeve, Y., Castelein, S., Jansen, W.S., Jansen, G.J., Roodbol, P.F., 2017. Nursing students' changing orientation and attitudes towards nursing during education: A two-year longitudinal study. Nurse Educ. Today 48, 19-24. https://doi.org/10.1016/j.nedt.2016.09.009

[9] Cassidy, S., 2015. Resilience Building in Students: The Role of Academic Self-Efficacy. Front. Psychol. 6. https://doi.org/10.3389/fpsyg.2015.01781

[10] Tempski, P., Santos, I.S., Mayer, F.B., Enns, S.C., Perotta, B., Paro, H.B.M.S., Gannam, S., Peleias, M., Garcia, V.L., Baldassin, S., Guimaraes, K.B., Silva, N.R., da Cruz, E.M.T.N., Tofoli, L.F., Silveira, P.S.P., Martins, M.A., 2015. Relationship among Medical Student Resilience, Educational Environment and Quality of Life. PLOS ONE 10, e0131535. https://doi.org/10.1371/journal.pone.0131535

[11] Wu, L.T., Low, M.M.J., Tan, K.K., Lopez, V., Liaw, S.Y., 2015. Why not nursing? A systematic review of factors influencing career choice among healthcare students: Factors influencing career choice. Int. Nurs. Rev. 62, 547-562. https://doi.org/10.1111/inr.12220

[12] Martin, A.J., 2013. Academic buoyancy and academic resilience: Exploring 'everyday' and 'classic' resilience in the face of academic adversity. Sch. Psychol. Int. 34, 488-500. https://doi.org/10.1177/0143034312472759

[13] Wright, M.O., Masten, A.S., 2005. Resilience Processes in Development, in: Goldstein, S., Brooks, R.B. (Eds.), Handbook of Resilience in Children. Springer US, Boston, MA, pp. 17-37. https://doi.org/10.1007/0-306-48572-9_2

[14] Cassidy, S., 2016. The Academic Resilience Scale (ARS-30): A New Multidimensional Construct Measure. Front. Psychol.

7. https://doi.org/10.3389/fpsyg.2016.01787

[15] Ahammed, Y., MacDonald, H., Reed, K., Naylor, P.J., Liu Ambrose, T., McKay, H., 2011. School-based physical activity does not compromise children's academic performance. Med. Sci. Sports Exerc. 39, 371 376. http://dx.doi.org/10.1017/S0140525X11000677 
[16] Liaw, S.Y., Wu, L.T., Lopez, V., Chow, Y.L., Lim, S., Holroyd, E., Tan, K.K., Wang, W., 2017. Development and psychometric testing of an instrument to compare career choice influences and perceptions of nursing among healthcare students. BMC Med. Educ. 17. https://doi.org/10.1186/s12909-017-0910-7

[17] Goel, S., Angeli, F., Dhirar, N., Singla, N., Ruwaard, D., 2018. What motivates medical students to select medical studies: a systematic literature review. BMC Med. Educ. 18. https://doi.org/10.1186/s12909-0181123-4

[18] Yousef, S., Athamneh, M., Masuadi, E., Ahmad, H., Loney, T., Moselhy, H.F., Al-Maskari, F., ElBarazi, I., 2017. Association between Depression and Factors Affecting Career Choice among Jordanian Nursing Students. Front. Public Health 5. https://doi.org/10.3389/fpubh.2017.00311

[19] Waddell, J., Spalding, K., Canizares, G., Navarro, J., Connell, M., Jancar, S., Stinson, J., Victor, C., 2015. Integrating a Career Planning and Development Program into the Baccalaureate Nursing Curriculum: Part I. Impact on Students' Career Resilience. Int. J. Nurs. Educ. Scholarsh. 12. https://doi.org/10.1515/ijnes-2014-0035

[20] Liew, J., Cao, Q., Hughes, J.N., Deutz, M.H.F., 2018. Academic Resilience Despite Early Academic Adversity: A Three-Wave Longitudinal Study on Regulation-Related Resiliency, Interpersonal Relationships, and Achievement in First to Third Grade. Early Educ. Dev. 29, 762-779. https://doi.org/10.1080/10409289.2018.1429766
[21] Bakhshialiabad, H., Bakhshi, M., Hassanshahi, G., 2015. Students\&rsquo; perceptions of the academic learning environment in seven medical sciences courses based on DREEM. Adv. Med. Educ. Pract. 195. https://doi.org/10.2147/AMEP.S60570

[22] Fallatah, H.I., Tekian, A., Park, Y.S., Al Shawa, L., 2015. The validity and reliability of the sixth-year internal medical examination administered at the King Abdulaziz University Medical College. BMC Med. Educ. 15, 10. https://doi.org/10.1186/s12909-015-02954

[23] Sutter, N., Paulson, S., 2014. Predicting College Students' Intention to Graduate: A Test of the Theory of Planned Behavior. UMI Dissertation Publishing.

[24] Beauvais, A.M., Stewart, J.G., DeNisco, S., Beauvais, J.E., 2014. Factors related to academic success among nursing students: A descriptive correlational research study. Nurse Educ. Today 34, 918-923. https://doi.org/10.1016/j.nedt.2013.12.005

[25] Pitt, V., Powis, D., Levett-Jones, T., Hunter, S., 2014. Nursing students' personal qualities: A descriptive study. Nurse Educ. Today 34, 1196-1200. https://doi.org/10.1016/j.nedt.2014.05.004

[26] Schneider, M., Preckel, F., 2017. Variables associated with achievement in higher education: A systematic review of meta-analyses. Psychol. Bull. 143, 565-600. https://doi.org/10.1037/bul0000098 